\title{
Managing non-suicidal self-injury using cognitive-behavioral therapy in a female adolescent
}

\author{
Bilel OUESLATI, Zeineb Salma ABBES-GHORBEL, Asma BOUDEN \\ Child and adolescent psychiatric unit, Razi Hospial, Tunisia
}

\section{Background and aim:}

In adolescents, self-mutilation may take place in two main contexts: suicidal and non-suicidal ones ${ }^{(1)}$. While remaining in the second context, which is the most frequent in adolescents; our work had as an aim to manage a teenager suffering from non-suicidal self-injury using a structured cognitive and behavioral therapy.

\section{Materials and methods:}

The patient was 14 years old. Psychotherapy was planned over 12 sessions. The first ten were weekly. The last two sessions, devoted to the follow-up, were spaced by two weeks. Selfmutilations were conceptualized as being related to a deficiency in assertiveness and stress management. Psychometric assessment was performed using Rathus assertiveness scale (2), Kutcher Adolescent Depression scale (KADS) (3) and Barratt Impulsiveness scale (BIS-11) ${ }^{(4)}$.

\section{Results:}

Stress management was approached using behavioral techniques. The role of social models had a crucial impact on the therapy. Later, we focused on assertiveness while strengthening the achievements in stress management. Role plays were the main behavioral used technique. On the other hand, we used two other approaches that straddle behaviorism and cognitivism in order to facilitate the transition to cognitive work (reality test and social models continuum).

\begin{tabular}{|l|l|l|l|}
\hline & Session 1 & Session 8 & Session 12 \\
\hline Harming oneself & $100 \%$ & $80 \%$ & $10 \%$ \\
\hline $\begin{array}{l}\text { Stress } \\
\text { management }\end{array}$ & $0 \%$ & $50 \%$ & $80 \%$ \\
\hline \multicolumn{2}{|c|}{$\begin{array}{l}\text { Table 1: Concivtions regarding harming moneself and stress management } \\
\text { strategies and their progression during the therapy }\end{array}$}
\end{tabular}

\section{References:}

Cognitive restructuring was used later. Final result was satisfactory. Scarifications did not recur after the ninth session (Figure 1). Rathus Scale score increased from 5 to 19 (Table 2).

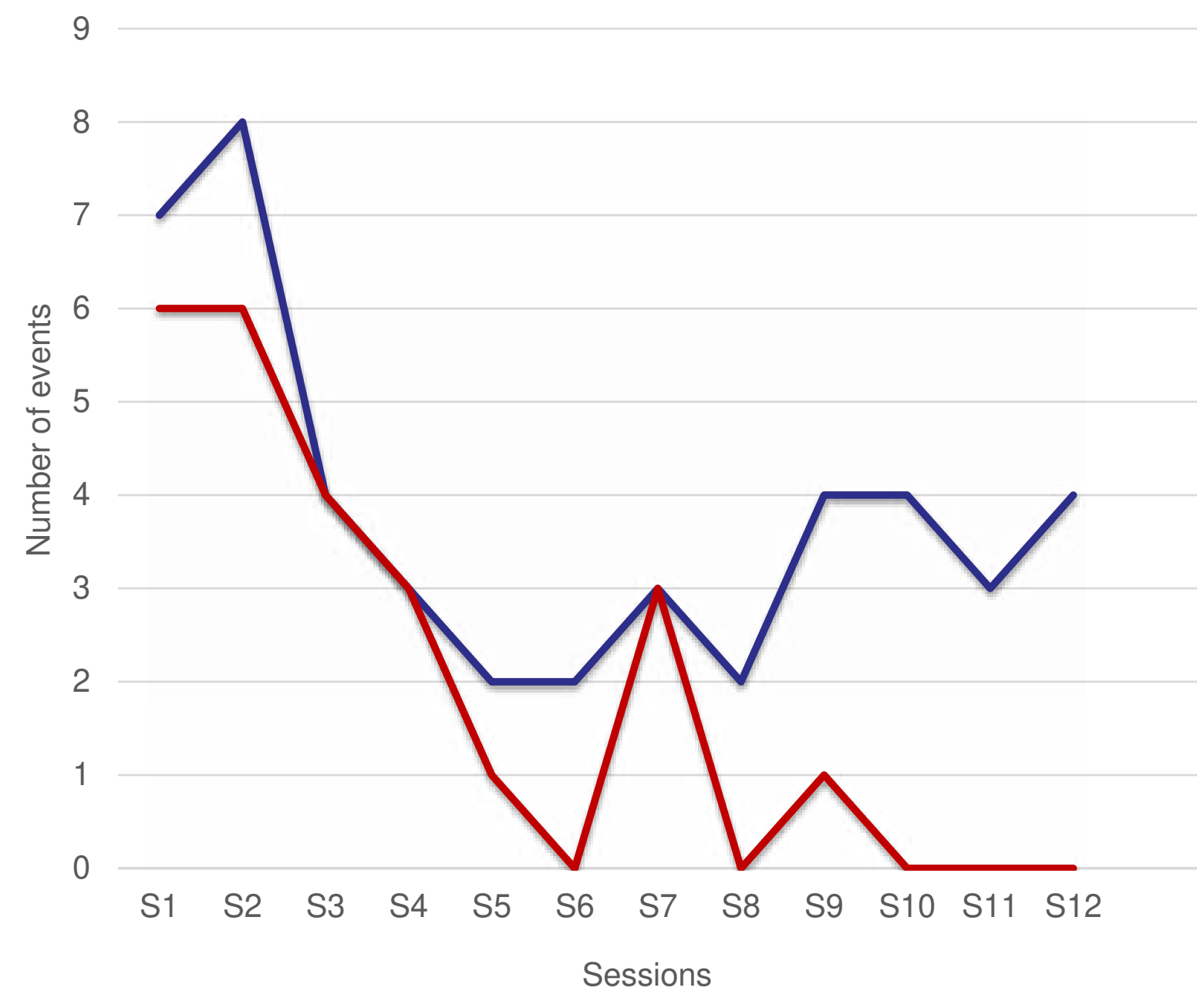

-Number of stressful events $\longrightarrow$ Number of self-mutilation episodes

Figure1: Self-mutilations vs stressful events' progression during the therapy

\begin{tabular}{|c|c|c|c|}
\hline & Initial evaluation & Session 8 & Session 12 \\
\hline Rathus scale (2) & 5 & 12 & 19 \\
\hline KADS scale ${ }^{(3)}$ & 4 & 4 & 3 \\
\hline BIS 11 scale ${ }^{(4)}$ & 77 & 75 & 71 \\
\hline
\end{tabular}

Table 2: Psychometric evaluation

Conclusions:

Psychotherapy is the first-line treatment for such patients. Although there are no pre-established protocols, cognitivebehavioral therapy is the most used approach. Its effectiveness has been illustrated in our work.

1-Pelkonen M, Marttunen R, Henriksson M, Lonnqvist J. Adolescent adjustment disorder: Precipitant stressors and distress symptoms of 89 outpatients. Eur Psychiatry. 2007;22(5):288-95.

2-Rathus SA. A 30-item schedule for assessing assertive behavior. Behav Ther. 1973;4(3):398-406.

3-Brooks S. The Kutcher Adolescent Depression Scale (KADS). Child and Adolesc Psychopharmacol News. 2004;9(5):4-6. 